\title{
CHARNOQUITÓIDES DO MACIÇO DE VÁRZEA ALEGRE: UM NOVO EXEMPLO DO MAGMATISMO CA-ALCALINO DE ALTO K NO ARCO MAGMÁTICO DO ESPÍRITO SANTO
}

\author{
J.C.Mendes ${ }^{1}$, I.McReath ${ }^{2}$, C.Wiedemann ${ }^{1}$, M.C.H.Figueiredo (in memorian) ${ }^{2}$
}

\begin{abstract}
O maciço intrusivo de Várzea Alegre localiza-se no centro do Espírito Santo e é representante do magmatismo tardi a pós-tectônico associado ao desenvolvimento do arco magmático de idade Brasiliana nessa região. Possui forma circunscrita, é inversamente zonado e está encaixado em orto e paragnaisses de grau anfibolito alto a granulito. Mostra no centro gabros que são envolvidos por dioritos/quartzo-dioritos e granitos megaporfiríticos. Este conjunto é circundado por uma extensa e irregular auréola de rochas charnoquitóides megaporfiríticas (Medeiros et al., 1994).

Os charnoquitóides têm textura ignea preservada e sua mineralogia é: plagioclásio, álcali-feldspato pertítico, OPX, biotita, hornblenda, ilmenita, magnetita, pirita, apatita, zircão e rara allanita. Os megacristais são de feldspato alcalino, plagioclásio e quartzo e a matriz tem granulação média a grossa e quando está apertada entre os megacristais é mais fina e ligeiramente recristalizada. Os cristais de OPX encontram-se parcialmente substituídos por biotita, anfibólio e minerais opacos e estão bem alterados. São observados cristais de feldspato alcalino substituindo plagioclásio e consideráveis variações nas concentrações de suas lamelas pertiticas.
\end{abstract}

A classificação química dessas rochas resulta nos seguintes tipos: opdalitos, jotunitos, OPX-quartzo-dioritos, e quartzo-mangeritos. Representam uma seqüência pouco expandida, possuindo teores de $\mathrm{SiO}_{2}$ variando de 54 a $65 \%$. Compreendem rochas metaluminosas ricas em $\mathrm{Ti}, \mathrm{P}, \mathrm{Zr}$, Bà e ETR, ligeiramente enriquecidas em $\mathrm{Fe}$ e $\mathrm{K}$, e pobres em $\mathrm{Mg}, \mathrm{Al} \mathrm{e} \mathrm{V}$, sendo variavelmente empobrecidas em $\mathrm{Ca}$, quando se compara com rochas de composição similar encontradas na literatura. Possuem algumas caracteristicas comparáveis a rochas da série mangerítica, mas suas concentrações mais altas de $\mathrm{Ca}$ e $\mathrm{Sr}$ e mais baixas de $\mathrm{K}$ e $\mathrm{Rb}$ (além das razões $\mathrm{K} / \mathrm{Rb}$ e $\mathrm{Rb} / \mathrm{Sr}$ bem inferiores) não permitem que sejam geoquimicamente associadas às rochas de tal série.

A assinatura geoquimica é compatível com um magmatismo Ca-alcalino de alto $\mathrm{K}$ álcali-cálcico enriquecido em Fe e elementos incompatíveis. O diagrama AFM da Figura 1 e o padrão de distribuição de elementos incompatíveis da Figura 2 exemplificam tal comportamento. As anomalias negativas de $\mathrm{Ti}, \mathrm{P}$ e $\mathrm{Nb}$ observadas nesta última figura têm sido consideradas como uma característica geoquímica de zona de subducção (Pearce, 1983). No diagrama R1 x R2 os charnoquitóides de Várzea Alegre posicionam-se preferencialmente no campo 3, típico de granitóides cálcio-alcalinos de alto $\mathrm{K}$ pós-tectônicos, como pode ser visto na Figura 3. Os altos teores de alguns elementos HFS não seriam esperados para rochas formadas em ambiente orogênico, uma vez que tais anomalias são associadas a metassomatismo mantélico

\footnotetext{
${ }^{1}$ Departamento de Geologia, Universidade Federal do Rio de Janeiro.

${ }^{2} \mathrm{DGG}$, Instituto de Geociências, Universidade de São Paulo.
} 
intra-placa. Dentro deste contexto, as rochas charnoquitóides de Várzea Alegre provavelmente sofreram contribuição de um manto previamente enriquecido em elementos incompatíveis, inclusive HFS.
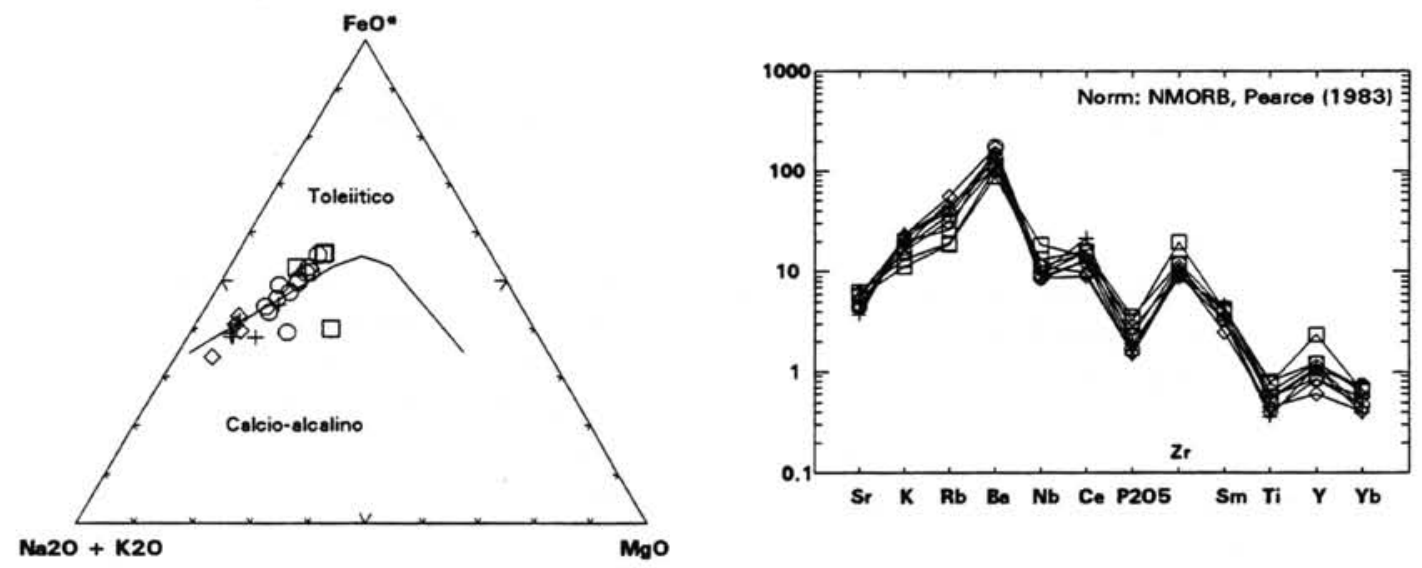

Figuras 1 e 2 - Diagramas AFM e de distribuição de elementos incompativeis. Símbolos: $\square$ : OPX-Quartzo-dioritos; O: Jotunitos; +: Opdalitos; ৩: Quartzo-mangeritos.

Como pode ser visto na Figura 4, os padrões de ETR são bem fracionados com suaves anomalias positivas de Eu. As concentrações variam bastante, com os valores de $\mathrm{La}$ oscilando entre cerca de 150 a 300 vezes o condrito e observa-se uma tendência geral dos conteúdos decrescerem com a diferenciação. Tais irregularidades na distribuição de ETR têm sido associadas a processos de equilíbrio cristal-liquido na rocha fonte. Considerando-se os padrões obtidos, não deve ter ocorrido significativo fracionamento de elementos terras raras entre os diversos intervalos composicionais.
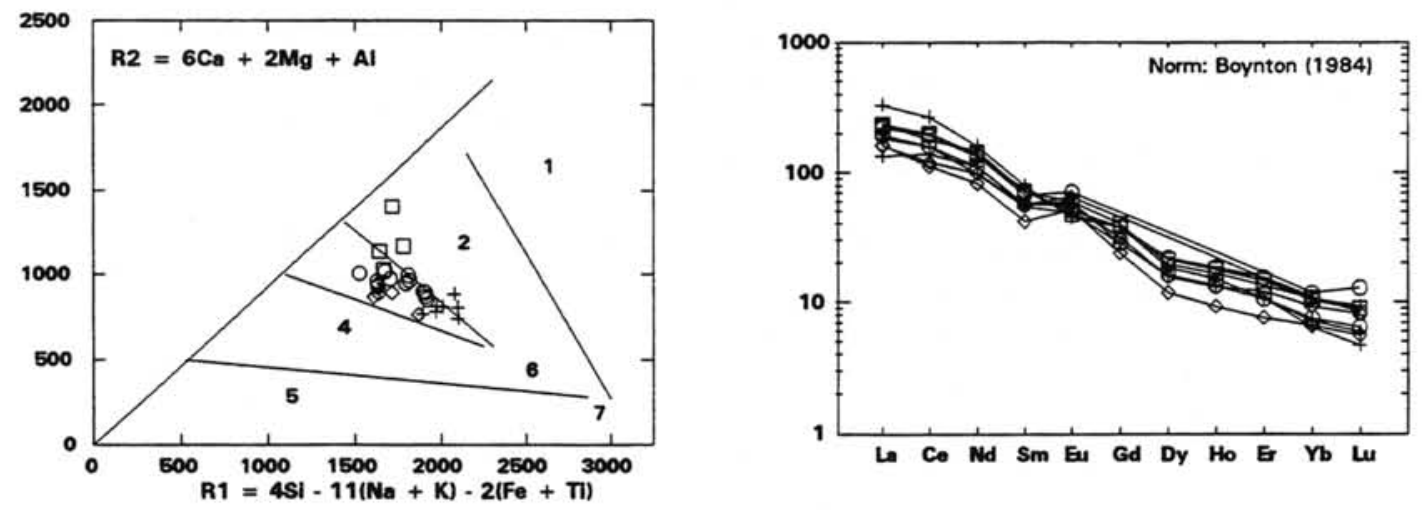

Figuras 3 e 4 - Diagrama R1xR2 e padrão de elementos terras raras. Símbolos: $\square$ : OPXQuartzo-dioritos; O: Jotunitos; +: Opdalitos; ৩: Quartzo-mangeritos.

O comportamento das amostras em gráficos nos quais são correlacionados elementos incompativeis versus elementos compativeis sugere que processos de cristalização fracionada e mistura de magmas tenham sido os responsáveis pela diversidade litológica encontrada. $\mathbf{O}$ quimismo é comparável a granitóides álcali-cálcicos maduros, de arco magmático, 
enriquecidos em Fe, elementos LIL e HFS e com razões HFS/LILE mais altas (Brown et al., 1984). O posicionamento dessas rochas se deu provavelmente num ambiente de transição, no qual a crosta ainda estava submetida a algum esforço de compressão, talvez contemporaneamente a um início de relaxamento em áreas adjacentes.

\section{Referências Bibliográficas}

BOYNTON, W.V. (1984) Cosmochemistry of the rare earth element: meteorite studies. In: HENDERSON, P. (Ed.) Rare Earth Element Geochemistry. Amsterdam, Elsevier, p.63114. (Developments in geochemistry, 2).

BROWN, G.C.; THORPE, R.S.; WEBB, P.C. (1984) The geochemical characteristics of granitoids in contrasting arcs and comments on magma sources. Journal of Geological Society London, v.141, p.413-426.

MEDEIROS, S.R.; MENDES, J.C.; WIEDEMANN, C.M. (1994) Feições diagnósticas do complexo intrusivo de Várzea Alegre, ES. In: CONGRESSO BRASILEIRO DE GEOLOGIA, 38., Camboriú, 1994. Boletim de resumos expandidos. Camboriú, SBG, vol.1, p.140-141.

PEARCE, J.A. (1983) Role of the sub-continental lithosphere in magma genesis at active continental margins. In: HAWKESWORTH, C.J.; NORRY, M.J. (Eds.), Continental basalts and mantle xenoliths. Shiva, Nantwich. p.230-249. 